\title{
Spinocerebellar ataxia type 28
}

INSERM

\section{Source}

INSERM. (1999). Orphanet: an online rare disease and orphan drug data base.

Spinocerebellar ataxia type 28. ORPHA:101109

Spinocerebellar ataxia type 28 (SCA28) is a very rare subtype of type I autosomal dominant cerebellar ataxia (ADCA type I; see this term). It is characterized by juvenile onset, slowly progressive cerebellar ataxia due to Purkinje cell degeneration. 